\title{
Alternative Sources OF SUPPly FOR STAND-AlONE AUTOMATION DEVICES ON SUPPORTS High-VOLTAGE LINES
}

\author{
Iosif Breido, Sofiya Voytkevich, Gennadiy Em, Vladimir Kaverin
}

Bulvar Mira 56, main bld. 140, 100027 Karaganda, Kazakhstan

\begin{abstract}
Currently, Kazakhstan and CIS countries no system diagnostics and protection elements of high-voltage power lines on the basis of local automation systems. At the same time a great need for cathodic protection systems of support elements, the system control leakage suspension insulators, sleet and snow build-up of deposits. The main obstacle to the establishment of such systems is the lack of energy sources. This paper is designed layout receivers electrostatic converters. Based on the developed equivalent circuits created a simulation model for the magnetic component of a resonant circuit.
\end{abstract}

Keyword: high-voltage lines; diagnostic system; simulation model; layout receiving devices; energy converters
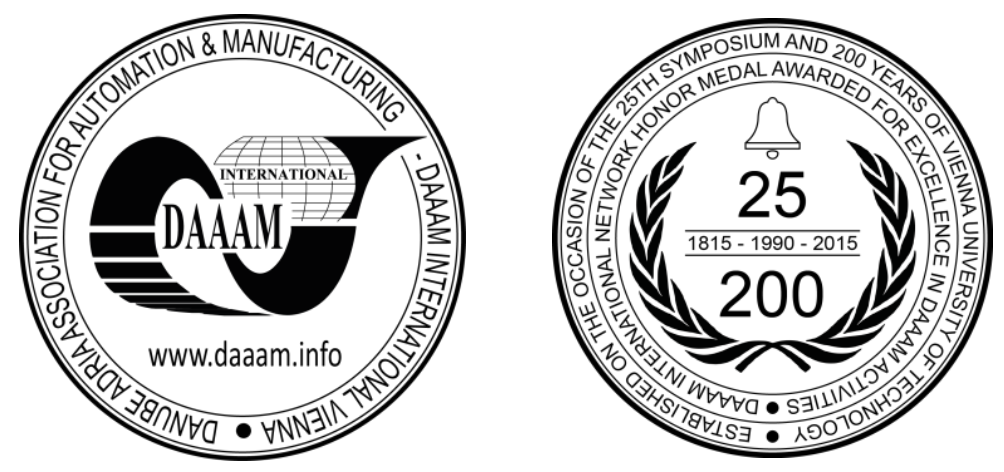

This Publication has to be referred as: Breido, I[osif]; Voytkevich, S[ofiya]; Em, G[ennadiy] \& Kaverin, V[ladimir] (2016). Alternative Sources of Supply for Stand-Alone Automation Devices on Supports High-Voltage Lines, Proceedings of the 26th DAAAM International Symposium, pp.0775-0779, B. Katalinic (Ed.), Published by DAAAM International, ISBN 978-3-902734-07-5, ISSN 1726-9679, Vienna, Austria

DOI:10.2507/26th.daaam.proceedings. 108 


\section{Introduction}

In Kazakhstan electricity for long distances is mainly passed overhead high-voltage power lines with a voltage of 220 - $500 \mathrm{kV}$. They are characterized by difficult operating conditions. Most of the high-voltage power lines located on a large distance from the human settlements and on difficult terrain.

Elements of support of high voltage lines are subject to electrochemical corrosion, influence of the atmospheric phenomena (rain, dust, snow).

Known works I.V. Semenov, G.M. Florianovich, A.V. Khoroshilov, M. Fontan, R. Staley, V. Kramar, V. Dushko, A. Rodkina, A. Zaiets, M. Barhalescu, C. Dumitrache, E. Oanta, A. Sabau, R. Kralikova, M. Andrejiova, E. Wessely which are aimed at study the mentioned effects [1-5].

Notable works A.F. Dyakov, I.I. Levchenko, A.S. Zasypkina, A.A. Alliluyeva, E.I. Satsuk, A.I. Bytkina, F.A. Dyakov, A.L. Kulikov, M.I. Fursanova, Yu.L. Bogatyrev, P.V. Kriksin, which are exploring ways, detect and combating these appearance [6-8].

However, system diagnostics and protection elements of the high-voltage power lines are absent because of the impossibility organization of low-voltage power supply. each support.

The use of wind power and solar panels are not economically profitable, since the power supply must be on

Thus it is expedient to use the energy transmitted over the power lines as an alternative power source for system diagnostics and protection.

\section{Research in the field of alternatives to energy sources}

Attempts to use for the purposes of power system diagnostics and protection of various alternative power sources, including wind power, and (or) the solar power plant, have not found wide practical application due to high cost, since they must be placed under each support.

In the surrounding area of the high-voltage line there are electric and magnetic fields of industrial frequency. The distance at which the distributed field of the wire line reaches the tens of meters.

The electric field high-voltage line is practically independent of the load and is fully determined by the voltage. Range distribution of the electric field is dependent on the voltage level of the high-voltage power lines. Range distribution of the magnetic field and its intensity depends on the value of the flowing current (the load line). It should also be noted that the high-voltage transmission lines in addition to the air electromagnetic fields of industrial frequency, are sources of high-frequency fields. This is because corona wires and partial discharges in the transformer windings.

On the other hand, a number of works that have practical applications. Studies [9-13] have shown that the electromagnetic fields generated during transportation of electric power can be efficiently used for active power and low-power power consumption sources.

From studies [9] follows that for the conversion of the electromagnetic field into electric energy is possible to use devices based on capacitive and inductive principles of conversion of the electromagnetic field. To convert the magnetic component of the electromagnetic field of industrial frequency emitted by the high-voltage line, it is suggested to use an inductor, and to convert electrical component to use a horizontal, parallel to the power line, the wire is one of the capacitor plates, and the second electrode is a wire high-voltage line.

The features of these receivers is the variable distance between the radiating element and the receiving part of the power line, as well as changing the dielectric constant of air, due to seasonal and daily changes in temperature, humidity and pressure.

Location scheme receivers energy converter with respect to the high-voltage power lines is presented in Figure 1 (a, b).
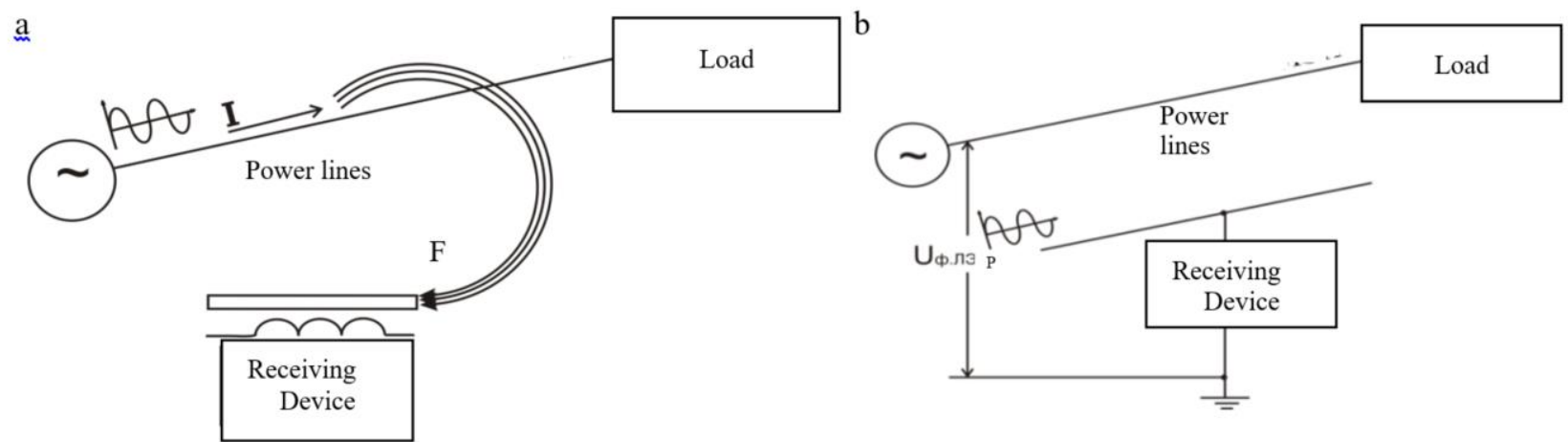

Fig. 1. Layout diagram of elements of active receivers with respect to the high-voltage power lines. (a) the magnetic component of the electromagnetic field; (b) the electrical component of the electromagnetic fields. 
As part of the receiving converter magnetic and electrical components of the electromagnetic field is used resonant magnetic circuit that provides current resonance [14].

\section{Simulation and experimental studies}

Simulation is an important part of scientific research [15]. In carrying out the calculation of the dependence of power as a function of load. Also it found that the maximum power load is given in the receiver with equal load resistance and internal resistance of the receiver.

Based on the developed equivalent circuits in MATLAB simulation model created transceiver system for the magnetic component of a resonant circuit. The analysis of the electrostatic converter equivalent circuit is shown in Figure 2 .

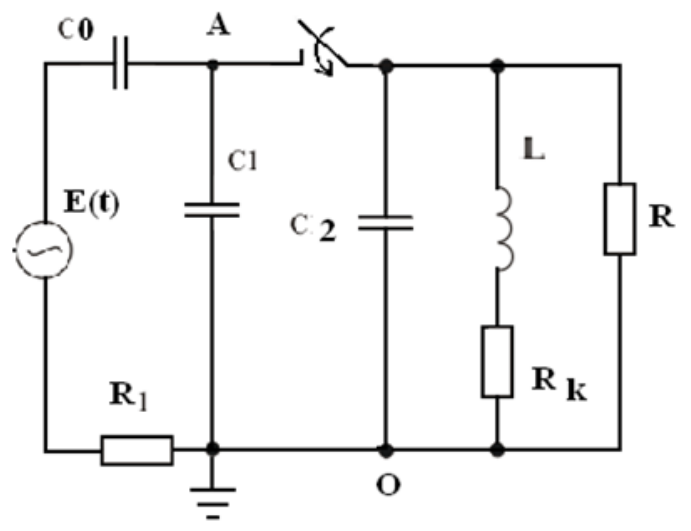

Fig. 2. The equivalent circuit of the electrostatic converter.

Where $\mathrm{E}(\mathrm{t})$ - voltage transmission line; $\mathrm{C}_{\mathrm{o}}$ - capacitance between the receiving antenna phase high-voltage line; $\mathrm{C}_{1}$ - capacitance between the transmitter and the receiving antenna at the ground equipment installation; $\mathrm{C}_{2}-$ the capacity of the inverter; $\mathrm{L}$ - inductance of the inductor to the inverter circuit; $\mathrm{R}_{1}$ - resistance between the ground wire and the return line; $\mathrm{R}_{\mathrm{k}}$ - active resistance of the inductor; $\mathrm{R}$ - load resistance converter.

Based on the equivalent circuit simulation model developed by the electrostatic converter in the medium and Electronics Workbench performed simulations. One of the experiments is shown in Figure 3.

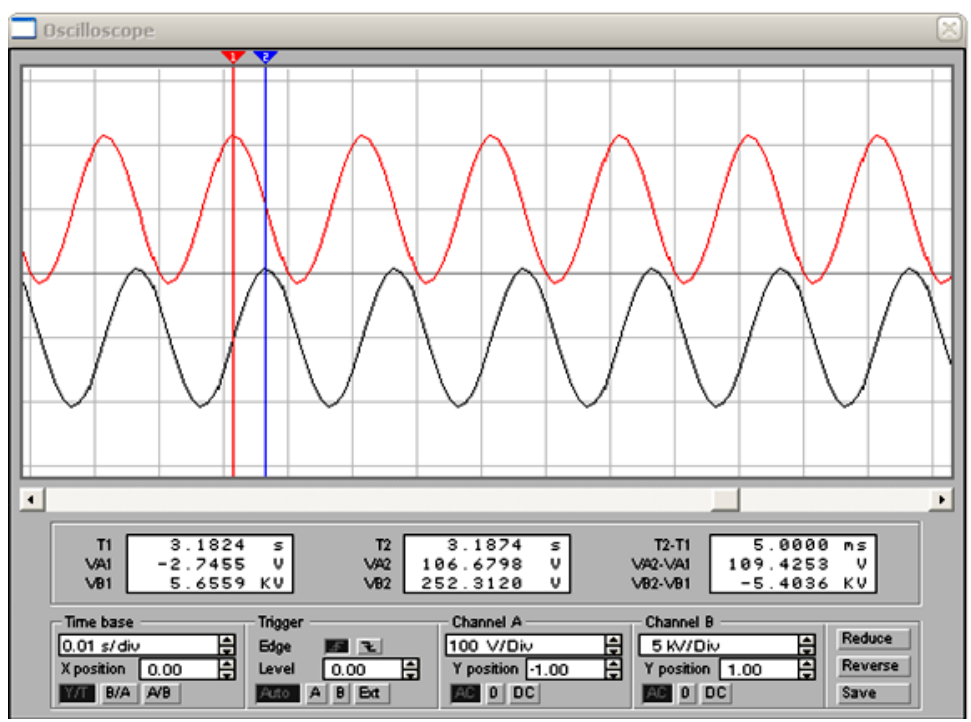

Fig. 3. Results of simulation mode of the electrostatic converter.

Based on analysis of the experiments found that the resistance $\mathrm{R}$ should be in the range $10^{5} \div 10^{6}$ Ohms, which contributes to a large value on the antenna voltage electrostatic converter. This is due to the fact that the reactance produced by the effective capacitance $\mathrm{C}_{\mathrm{o}}$ at power frequency is $10^{7} \div 10^{8} \mathrm{Ohms}$.

The amplitude of the voltage converter on the antenna $-5 \mathrm{kV}$. The currents in the branches with the capacity of the inverter and the inductive component and $25.75 \mathrm{~mA} 15.43 \mathrm{~mA}$, ie circuit current resonance occurs.

Load resistance $3 \mathrm{kOhm}$ is included in the branch with inductor. The active power consumed by the load is 78 $\mathrm{W}$ at a value of inductance of $500 \mathrm{Hn}$. 
The upper oscillogram - the change in voltage at the antenna transmitter; lower oscillogram - the current in the inductive element to the branch (Figure 3).

It was conducted field research on converters, in which the experiments were conducted with electrostatic and electromagnetic converters and transmitters with energy lightning protection.

\section{The results of studies}

For the electrostatic converter with the antenna was defined current and voltage as a function of the distance between the axes of the high-voltage power lines and antennas at a constant load with a resistance of 15 Ohms. By changing the distance between the axes of power line and the antenna in the range $55 \div 5 \mathrm{~m}$ output voltage acceptance unit varies within the range $0,4 \div 16,2 \mathrm{~V}$, the current value of the load was varied in the range of $0,027 \div 1,1 \mathrm{~A}$.

Transmitters electromagnetic type defined according to the current and voltage as a function of load resistance, variable in the range $0 \div 300 \mathrm{ohms}$. The voltage across the load acceptance unit was varied in the range of $0 \div 11 \mathrm{~V}$, and the no-load voltage was $14 \mathrm{~V}$. The value of the current in the load varies in the range of $0.021 \div 0.25 \mathrm{~A}$, the short-circuit current of inductor was $0.25 \mathrm{~A}$.

For the energy converter of the lightning protection derived dependence current and voltage as a function of load resistance, variable in the range $0 \div 88 \mathrm{Ohm}$. The voltage across the load acceptance unit varied in the range of $0 \div$ $149 \mathrm{~V}$ and the no-load voltage is $460 \mathrm{~V}$. The current in the load varies in the range of $2.5 \div 0 \mathrm{~A}$, the short-circuit current of the lightning protection to the ground was $2.5 \mathrm{~A}$.

Placing receiving devices electrostatic and electromagnetic energy converter of high-voltage power line in the field is associated with certain difficulties. The difficulties associated with the need for additional facilities along the high-voltage line and to ensure their safe operation. For power automation devices to be placed on supports highvoltage line and blocks of cathodic protection, power of such converters is not enough.

\section{Conclusion}

The analysis has shown a number of problems with the elements of support that arise in the operation of highvoltage power lines. It is electrochemical corrosion, destructive elements underground. The same dust, resulting in the insulator; sleet, which leads to a broken wire; wind, due to which there is overlap between the wires and so on.

The most effective solution to the above problems is to create a diagnostic system that will prevent damage and protect the system from electrochemical corrosion.

The lack of such systems is associated with the lack of power supply. The use of wind power and solar panels is expensive, because it requires the installation source on each support.

Energy converter has been developed by induced electromagnetic field of high-voltage power lines. Converter circuit has been developed; simulation model has been developed, based on the equivalent circuit. There were also carried out field research of converter.

However, for the power supply of automation devices to be placed on high-voltage supports and blocks of cathodic protection, power of this converter is not enough.

To power converter having the necessary capacity to supply cathodic protection of supports high-voltage line and the complex automation devices, placed on supports, power converters can be referred a lightning protection.

\section{References}

[1] I.V. Semenov, G.M. Florianovich, A.V. Khoroshilov. Corrosion and Corrosion Protection. Fizmatlit Publishing, 2002.

[2] M. Fontana, R. Staley. Advances in science and technology for corrosion protection against it: stress-corrosion cracking, 1985.

[3] V.Kramar, V.Dushko, A. Rodkina, A.Zaiets. Influence of Stress-corrosion Fractures on Potential of Shipbuilding Metals in the Sea Water. In Annals of DAAAM for 2014\& Proceedings of 25th International DAAAM Symposium. Vienna: DAAAM International, 2014. ISBN 978-3-901509-73-5. ISSN 1726-9679.

[4] M.Barhalescu, C. Dumitrache, E. Oanta, A.Sabau. Improving corrosion resistance of metallic materials by electrical discharges in impulses. In Annals of DAAAM for 2009\& Proceedings of 20th International DAAAM Symposium. Vienna: DAAAM International, 2009. ISBN 978-3-901509-73-5. ISSN 1726-9679.

[5] R. Kralikova, M. Andrejiova, E. Wessely. Energy Saving Techniques and Strategies for Illumination in Industry. In Annals of DAAAM for 2014\& Proceedings of 25th International DAAAM Symposium. Vienna: DAAAM International, 2014. ISBN 978-3-901509-73-5. ISSN 1726-9679.

[6] A.F. Dyakov, I.I. Levchenko, A.S. Zasipkin, A.A. Alliluev, E.I. Satsuk, A.I. Bytkin, F.A. Dyakov. Information systems control ice loads on overhead lines. Energetic, NTF "Energoprogress", volume 11, 2005, pp. 20-25.

[7] A.L. Kulikov. A method for detecting icing formations on the wire and lightning protection power lines. RF patent №2409882, 2010.

[8] M.I. Fursanov, Y.L. Bogatyrev, P.V. Kriksin. Diagnosis of $110 \mathrm{kV}$ power line isolation under operating voltage. Energy and Management, volume 11 2011. - № 2 (59). pp. 28-36.

[9] Ya. I. Frenkel theory of the phenomena of atmospheric electricity. Moscow, 2007. 160 p. 
[10] I.V. Breido, V.V. Kaverin, E.B. Potemkina, S.B. Kochetkov. Analysis of ways to convert atmospheric electricity. International scientific conference "Science and education - the leading factor of strategy" Kazakhstan-2030 ". Karaganda, KarGTU Publishing, 2009, pp. 123-125.

[11] I.V. Breido, V.V. Kaverin, E.B. Potemkina, L.M. Lapina. Research and development of low-power energy sources, based on the use of electrochemical processes occurring in the soil, and atmospheric electricity. Proceedings of the scientific and technical community "Qakhaq." Almaty, volume 3, 2009, pp. 7-12.

[12] I.V. Breido, V.V. Kaverin, E.B. Potemkina, S.V. Voytkevich. Optimizing the load low-power transmitter of atmospheric electricity: International Conference "Future issues of the world of science 2009",Bulgaria, Sofia, 2010, pp. 24-26.

[13] I.V. Breido, V.V. Kaverin, A.Zh. Janat. Investigation of the characteristics of the primary device of the electromagnetic field: VI International Scientific and Practical Conference "Поглед върху световната", Вulgaria, Sofia, 2010, pp. 37-39.

[14] Yu.F.Skripnikov. The oscillation circuit. Moscow, 1970, 128 p.

[15] S.Voytkevich, I. Breido, V. Kaverin. Universal Mathematical Model of Leakage Currents and Currents Spread on Elements of High-Voltage Pillar. In Annals of DAAAM for 2014\& Proceedings of 25th International DAAAM Symposium. Vienna: DAAAM International, 2014. ISBN 978-3-901509-73-5. ISSN 1726-9679. 